\title{
Seasonal Diversity of Arbuscular Mycorrhizal Fungi in Mangroves of Goa, India
}

\author{
James D'Souza and Bernard Felinov Rodrigues \\ Department of Botany, Goa University, Taleigao, Goa 403 206, India \\ Correspondence should be addressed to James D’Souza; james2442@gmail.com
}

Received 27 September 2012; Revised 24 November 2012; Accepted 31 December 2012

Academic Editor: Curtis C. Daehler

Copyright (c) 2013 J. D'Souza and B. F. Rodrigues. This is an open access article distributed under the Creative Commons Attribution License, which permits unrestricted use, distribution, and reproduction in any medium, provided the original work is properly cited.

\begin{abstract}
Seasonal dynamics of arbuscular mycorrhizal (AM) fungal community composition in three common mangrove plant species, namely, Acanthus ilicifolius, Excoecaria agallocha, and Rhizophora mucronata, from two sites in Goa, India, were investigated. In all three species variation in AM fungal spore density was observed. Maximum spore density and AM species richness were recorded in the premonsoon season, while minimum spore density and richness were observed during monsoon season at both sites. A total of 11 AM fungal species representing five genera were recorded. Acaulospora laevis was recorded in all seasons at both sites. Multivariate analysis revealed that season and host coaffected AM spore density and species richness with the former having greater influence than the latter.
\end{abstract}

\section{Introduction}

Mangroves are a type of coastal woody vegetation that fringes muddy saline shores and estuaries in tropical and subtropical regions [1]. They are characterized by high levels of productivity and fulfill essential ecological functions, harbouring precious natural resources [2]. Mangroves have become the center of many conservation and environmental issues because of the beneficial effects they have on the coastal environment. Recent evidence suggests that growth of mangroves is limited primarily by phosphorus $(\mathrm{P})$ availability as it is adsorbed and coprecipitated within carbonate-dominated environments [3]. Phosphate solubilizers, $\mathrm{N}$ fixers, and AM fungi are known to interact in the rhizosphere soils [4] where hyphae of AM fungi assist in accessing nutrients by extending beyond the root depletion zone [5]. These fungi also alleviate salt stress and aid physiological processes such as osmotic adjustment via accumulation of soluble sugars in root cells [6] and contribute to the nutritional status of plants [7]. They play a crucial role in determining plant diversity, production, and species composition [8]. The seasons are a result of the tilt of Earth's axis that causes variation in environmental conditions and spore density, and community composition of AM fungi are influenced by these changes.
To understand the ecology and function of plant-fungus associations in natural ecosystems, it is necessary to clarify seasonal diversity of AM fungi, providing insight into the factors and processes regulating ecosystem development [9]. Studies on the occurrence and diversity of AM fungi from different mangrove plants have been documented $[2,10]$. However, no studies have been reported on the seasonal dynamics of AM fungi in mangroves. In this paper, spore density and species richness pattern of AM fungi in relation to seasons have been elucidated.

\section{Methodology}

2.1. Study Sites and Sample Collection. Two study sites, namely, Terekhol $\left(15^{\circ} 72^{\prime} 28^{\prime \prime} \mathrm{N}\right.$ and $\left.73^{\circ} 72^{\prime} 99^{\prime \prime} \mathrm{E}\right)$ with a stretch of $28 \mathrm{Km}$ and Zuari $\left(15^{\circ} 32^{\prime} 56^{\prime \prime} \mathrm{N}\right.$ and $\left.73^{\circ} 89^{\prime} 71^{\prime \prime} \mathrm{E}\right)$ having $67 \mathrm{Km}$, were selected for the study. Three dominant plant species, namely, Acanthus ilicifolius L. (Acanthaceae), Excoecaria agallocha L. (Euphorbiaceae), and Rhizophora mucronata Poir. (Rhizophoraceae), common to the two sites, were undertaken for the study. The tropical environment at both sites is warm and humid, with marshy soils. Mean temperature range is $22-35^{\circ} \mathrm{C}$ and average annual rainfall 
$2500 \mathrm{~mm}$. Mangroves species were identified using the local floras [11]. Rhizosphere soil samples were randomly collected in the premonsoon (March 2009-May 2009), monsoon (July 2009-Sep 2009), and postmonsoon (Oct 2009-Feb 2010) seasons from the two sites. The samples were placed in polyethylene bags, transported to the laboratory, and stored at $4^{\circ} \mathrm{C}$ until processed. Rhizosphere soil of individual plants was air dried at room temperature, sieved (mesh size $720 \mu$ ), and divided into two parts, one for isolation, enumeration, and identification of AM spores and the other for preparation of trap cultures.

2.2. Soil Analyses. Three soil samples from each of the study site were separately collected in polyethylene bags from a depth of $0-25 \mathrm{~cm}$, air dried in the laboratory before passing through a $2 \mathrm{~mm}$ sieve, and mixed thoroughly to obtain a composite sample. Soil pH was measured in soil water $(1: 2)$ suspension using a pH meter (LI 120 Elico, India). Electrical Conductivity (EC) was measured at room temperature in $1: 5$ soil suspension, using a conductivity meter (CM-180 Elico, India). Standard soil analysis techniques, namely, Walkley and Black rapid titration method [12] and Bray and Kurtz method [13], were employed for determination of organic carbon and available $\mathrm{P}$, respectively. Available potassium was estimated by ammonium acetate method [14] using a flame photometer (Systronic 3292). Available zinc (Zn), copper $(\mathrm{Cu})$, manganese $(\mathrm{Mn})$, and iron $(\mathrm{Fe})$ were quantified by DTPA-CaCl 2 -TEA method [15] using an Atomic Absorption Spectrophotometer (AAS 4139).

2.3. Trap Cultures, Isolation, and Taxonomic Identification of AM Fungal Spores. For identification of AM species, trap cultures were prepared in pots using field soil and sterile sand (1:1). Solenostemon scutellarioides (L.) Codd was used as the catch plant and the pots were maintained in a polyhouse at $27^{\circ} \mathrm{C}$. All cultures were provided a $14 \mathrm{~h}$ day/10 h night photoperiod for six months. The pots were watered when required, and Hoagland's solution minus $\mathrm{P}$ was added fortnightly. Intact and nonparasitized spores used for identification, obtained from both rhizosphere soil samples and trap cultures, were isolated using wet sieving and decanting technique [16]. Identification was based on spore morphology and subcellular characteristics $[17,18]$.

2.4. Diversity Studies and Statistical Analysis. Diversity studies were conducted for each site separately by calculating Simpson's Index of Diversity $1-D$ [19] $D=1-\Sigma\left(P_{i}\right)^{2}$, where $P_{i}=n_{i} / N\left(n_{i}\right.$, the relative abundance (RA) of the species calculated as the proportion of individuals of a given species to the total number of individuals in a community, $N)$. Shannon diversity index $\left(H^{\prime}\right)$ is commonly used to characterize species diversity in a community, accounting for both abundance and evenness of the species present, $H=-\Sigma\left(P_{i} \ln \left(P_{i}\right)\right)$ [20]. Species richness (SR) is the number of species present. Species evenness $(E)$, which indicates the distribution of individuals within species, was calculated by using the following formula: $\Sigma\left(H^{\prime}\right)=H^{\prime} / H_{\max }^{\prime}$, where $H_{\text {max }}^{\prime}=\ln (\mathrm{SR})$.

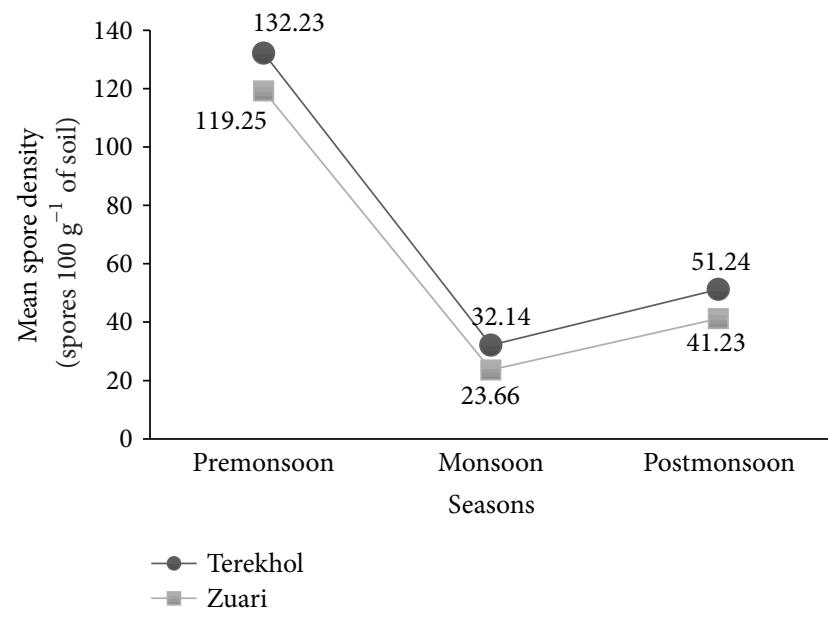

FIGURE 1: Mean spore density in rhizosphere soils of mangrove plant species in different seasons at the two study sites.

Pearson's correlation coefficient was calculated to assess the relationship between spore density and species richness at each site, using WASP software (Web Based Agricultural package) $2.0(P \leq 0.05)$. Relative abundance of AM fungal species common to all seasons was correlated with soil $\mathrm{pH}, \mathrm{P}$, and EC $(P \leq 0.05)$. Data on seasons and host coaffect the AM fungal spore density, species richness, and Shannon-Weiner diversity index was analyzed using multivariate analysis of variance (MANOVA). The statistically significant difference was determined at $P \leq 0.05$.

\section{Results}

3.1. Soil Analyses. Results of the soil physicochemical analyses are depicted in Table 1 . The study revealed acidic soils ( $\mathrm{pH}$ range 5.5-6.8) at both sites. Electrical Conductivity (EC) ranged from 4.03 to $8.49 \mathrm{dSm}^{-1}$. Organic carbon content was higher in the premonsoon season at both study sites. Soils at both sites were deficient in P. Levels of micronutrients such as $\mathrm{Cu}, \mathrm{Zn}, \mathrm{Mn}$, and Fe varied between the two study sites.

3.2. AM Fungal Spore Density. Sitewise results of the seasonal variations in spore density of AM fungi in the three mangrove plant species undertaken for the study are depicted in Table 2. Spore density varied significantly between the seasons and mangrove species. At both sites the mean spore density was significantly higher in the premonsoon season compared to monsoon and postmonsoon seasons (Figure 1). Maximum spore density was recorded for A. ilicifolius (230 spores $100 \mathrm{~g}^{-1}$ ) at the Terekhol site, while maximum spore density was recorded for E. agallocha (186 spores $100 \mathrm{~g}^{-1}$ ) at the Zuari site. Minimum spore density was recorded for $R$. mucronata at both sites.

3.3. Distribution and Relative Abundance (RA) of AM Species. A total of 11 AM fungal species representing five genera were recorded. Glomus was the dominant genus followed by Acaulospora, Rhizophagus, Funneliformis, and Racocetra. In 
TABLE 1: Soil physicochemical analyses of the study sites.

\begin{tabular}{lcccccc}
\hline \multirow{2}{*}{ Soil characteristics } & \multicolumn{2}{c}{ Premonsoon } & \multicolumn{2}{c}{ Monsoon } & \multicolumn{2}{c}{ Postmonsoon } \\
& Terekhol & Zuari & Terekhol & Zuari & Terekhol & Zuari \\
\hline $\mathrm{pH}$ & $6.5 \pm 0.12$ & $5.9 \pm 0.08$ & $6.8 \pm 0.07$ & $6.2 \pm 0.02$ & $6.7 \pm 0.19$ & $5.5 \pm 0.10$ \\
$\mathrm{EC}\left(\mathrm{dSm}^{-1}\right)$ & $4.12 \pm 1.02$ & $8.19 \pm 1.64$ & $4.03 \pm 1.79$ & $8.11 \pm 1.24$ & $4.30 \pm 1.12$ & $8.49 \pm 1.24$ \\
$\mathrm{OC}(\%)$ & $4.79 \pm 1.12$ & $3.61 \pm 1.29$ & $4.01 \pm 1.37$ & $3.01 \pm 1.02$ & $4.45 \pm 1.41$ & $3.12 \pm 1.06$ \\
$\mathrm{P}(\mathrm{g} / \mathrm{kg})$ & $0.17 \pm 0.02$ & $0.13 \pm 0.01$ & $0.16 \pm 0.04$ & $0.14 \pm 0.06$ & $0.13 \pm 0.01$ & $0.11 \pm 0.01$ \\
$\mathrm{~K}(\mathrm{~g} / \mathrm{kg})$ & $63.23 \pm 2.12$ & $87.96 \pm 4.12$ & $68.14 \pm 1.96$ & $81.28 \pm 2.12$ & $70.34 \pm 3.16$ & $85.12 \pm 2.12$ \\
$\mathrm{~N}(\mathrm{~g} / \mathrm{kg})$ & $0.54 \pm 0.06$ & $0.73 \pm 0.03$ & $0.57 \pm 0.04$ & $0.79 \pm 0.03$ & $0.61 \pm 0.02$ & $0.81 \pm 0.05$ \\
$\mathrm{Zn}(\mathrm{g} / \mathrm{kg})$ & $0.049 \pm 0.01$ & $0.030 \pm 0.01$ & $0.031 \pm 0.01$ & $0.029 \pm 0.04$ & $0.043 \pm 0.01$ & $0.032 \pm 0.01$ \\
$\mathrm{Mn}(\mathrm{g} / \mathrm{kg})$ & $0.042 \pm 0.04$ & $0.029 \pm 0.04$ & $0.033 \pm 0.04$ & $0.021 \pm 0.04$ & $0.037 \pm 0.04$ & $0.026 \pm 0.04$ \\
$\mathrm{Cu}(\mathrm{g} / \mathrm{kg})$ & $0.069 \pm 0.02$ & $0.051 \pm 0.01$ & $0.041 \pm 0.01$ & $0.032 \pm 0.01$ & $0.052 \pm 0.01$ & $0.040 \pm 0.01$ \\
$\mathrm{Fe}(\mathrm{g} / \mathrm{kg})$ & $0.189 \pm 0.06$ & $0.621 \pm 0.02$ & $0.112 \pm 0.04$ & $0.511 \pm 0.07$ & $0.143 \pm 0.08$ & $0.563 \pm 0.03$ \\
\hline
\end{tabular}

Data presented are means of three readings at each season; \pm indicates S.E.

TABLE 2: Seasonal variation in spore density of AM fungi in selected mangrove plant species at two study sites.

\begin{tabular}{|c|c|c|c|}
\hline \multirow{2}{*}{ Sr. no. } & \multirow{2}{*}{ Plant species } & \multicolumn{2}{|c|}{ Spore density (spores $100 \mathrm{~g}^{-1}$ of soil) } \\
\hline & & Terekhol site & Zuari site \\
\hline \multirow[t]{4}{*}{1} & Acanthus ilicifolius L. ${ }^{\mathrm{a}}$ & & \\
\hline & Premonsoon season & $230.00 \pm 9.21^{\mathrm{a}}$ & $149.00 \pm 5.61^{\mathrm{a}}$ \\
\hline & Monsoon season & $40.00 \pm 4.41^{\mathrm{c}}$ & $35.00 \pm 3.52^{c}$ \\
\hline & Postmonsoon season & $76.00 \pm 3.56^{\mathrm{b}}$ & $67.00 \pm 5.45^{\mathrm{b}}$ \\
\hline \multirow[t]{4}{*}{2} & Excoecaria agallocha L. ${ }^{\mathrm{b}}$ & & \\
\hline & Premonsoon season & $128.00 \pm 8.57^{\mathrm{a}}$ & $186.00 \pm 9.32^{\mathrm{a}}$ \\
\hline & Monsoon season & $20.00 \pm 2.35^{\mathrm{c}}$ & $27.00 \pm 2.41^{\mathrm{c}}$ \\
\hline & Postmonsoon season & $49.00 \pm 4.25^{\mathrm{b}}$ & $56.00 \pm 3.24^{\mathrm{b}}$ \\
\hline \multirow[t]{4}{*}{3} & Rhizophora mucronata Poir. ${ }^{c}$ & & \\
\hline & Premonsoon season & $38.00 \pm 5.24^{\mathrm{a}}$ & $22.00 \pm 2.98^{\mathrm{b}}$ \\
\hline & Monsoon season & $7.00 \pm 1.20^{c}$ & $21.00 \pm 7.37^{\mathrm{b}}$ \\
\hline & Postmonsoon season & $17.45 \pm 2.56^{\mathrm{a}}$ & $24.00 \pm 8.23^{\mathrm{a}}$ \\
\hline
\end{tabular}

Means in a column for a mangrove species followed by a different superscripts indicate significant differences ( $n=6$ for each season, $n=54$ overall, $P \leq 0.05$ ).

the present study two sporocarp species were recovered, $G$. aggregatum and G. rubiforme. Identification of AM fungal species was confirmed by trap culture method where no additional AM fungal species were recovered. Within AM species the highest RA was recorded for $R$. intraradices followed by $A$. scrobiculata, A. laevis, and A. bireticulata, and the lowest RA was recorded for R. gregaria. Acaulospora laevis was recovered in all three seasons, $R$. intraradices, and $R$. gregaria were recorded in two seasons from both sites, while G. nanolumen, R. fasciculatus, and G. multicaule were recorded in only one season from either site (Table 3 ). In the present study RA of dominant AM fungal species showed no significant correlation with soil $\mathrm{pH}, \mathrm{P}$, or EC values $(P \geq$ 0.05) (Table 4).

3.4. AM Fungal Species Richness and Species Evenness . Species richness in combined sites was maximum in premonsoon (9 species) and minimum in the monsoon season (4 species). Correlation analysis indicated that the spore density in premonsoon was significantly correlated with species richness at both sites (Terekhol $r=0.726$; Zuari $r=0.645$;
$P \leq 0.05)$ while no significant correlation was observed in either postmonsoon or monsoon season in either site (Table 5). Species evenness was maximum in postmonsoon season in both sites, and Shannon-Weiner $(H)$ and Simpson's indices showed variation between the different seasons (Table 6). Multivariate analysis revealed that seasons $\left(F_{2,26}=2.346\right.$; $P<0.001)$ and host $\left(F_{2,18}=1.854 ; P<0.001\right)$ coaffected AM fungal spore density and species richness. The seasons had a greater influence than host species as evidenced by higher $F$ values; however the interaction was found to be nonsignificant.

\section{Discussion}

Variation in $\mathrm{pH}$ and EC levels in the mangrove soils observed in the present study may be attributed to the constant flushing of tidal water, leading to deposition of salts [21]. Soils at both of the study sites were deficient in available P. It is reported that nearly $80-85 \%$ of $\mathrm{P}$ is made unavailable to plants due to fixation and immobilization [22]. Degradation of litter in mangrove ecosystems is active and continuous, resulting 
TABLE 3: Seasonal variation in relative abundance of AM fungi in the selected study sites.

\begin{tabular}{|c|c|c|c|c|c|c|}
\hline \multirow{2}{*}{ AM fungal species } & \multicolumn{2}{|c|}{ Premonsoon } & \multicolumn{2}{|c|}{ Monsoon } & \multicolumn{2}{|c|}{ Postmonsoon } \\
\hline & Terekhol & Zuari & Terekhol & Zuari & Terekhol & Zuari \\
\hline Rhizophagus intraradices (Schenck and Smith) Walker and Schüßler & 18.68 & 15.71 & 58.82 & 42.16 & - & - \\
\hline Glomus multicaule Gerdemann and Bakshi & 14.14 & - & - & - & - & - \\
\hline Glomus aggregatum Schenck and Smith & - & 10.72 & 10.29 & - & - & 15.64 \\
\hline Rhizophagus fasciculatus (Thaxter) Walker and Schüßler & - & - & - & - & 20.42 & - \\
\hline Funneliformis geosporum (Nicol. and Gerd.) Walker and Schüßler & - & - & - & - & 7.04 & 16.32 \\
\hline Glomus nanolumen Koske and Gemma & 9.84 & - & - & & - & - \\
\hline Glomus rubiforme Gerdemann and Trappe & - & 13.24 & - & 25.30 & - & - \\
\hline Acaulospora bireticulata Rothwell and Trappe & 8.83 & 31.67 & & - & - & - \\
\hline Acaulospora laevis Gerdemann and Trappe & 9.84 & 33.41 & 30.88 & 32.53 & 23.94 & 25.85 \\
\hline Acaulospora scrobiculata Trappe & 33.83 & - & - & - & 35.91 & 48.97 \\
\hline Racocetra gregaria (Schenck and Nicolson) Oehl, Souza, and Sieverd & 4.79 & 5.23 & - & - & 12.67 & 8.84 \\
\hline
\end{tabular}

All values are means of the composite sample of three plant species for each season.

TABLE 4: Pearson's correlation coefficient ( $r$ value) between relative abundance of dominant AM fungal species and soil pH, $\mathrm{P}$, and EC at the two study sites.

\begin{tabular}{|c|c|c|c|c|c|c|}
\hline \multirow{2}{*}{ Ecological parameters } & \multicolumn{3}{|c|}{ Terekhol site } & \multicolumn{3}{|c|}{ Zuari site } \\
\hline & Premonsoon & Monsoon & Postmonsoon & Premonsoon & Monsoon & Postmonsoon \\
\hline RA versus soil pH & 0.535 & 0.071 & 0.393 & 0.070 & 0.475 & 0.327 \\
\hline RA versus $P$ & 0.423 & 0.475 & 0.417 & 0.429 & 0.563 & 0.311 \\
\hline RA versus EC & 0.512 & 0.326 & 0.418 & 0.419 & 0.375 & 0.426 \\
\hline
\end{tabular}

RA: relative abundance; P: soil phosphorus; EC: electrical conductivity. $(P \leq 0.05)$; all values are means of the composite sample of three plant species for each season.

in the release of various acids during hydrolysis of tannins [23] and the oxidation of iron sulfide (pyrite) that releases dissolved ferrous iron [24], that are known to shift soils towards more acidic conditions. The present study revealed a high organic carbon content in the mangrove sediments, and its degradation resulting in low $\mathrm{pH}$ [23]. Concentration of Fe was higher at Zuari than at Terekhol. At the Zuari site, maximum concentration of $\mathrm{Fe}$ was recorded in the premonsoon season. Earlier study suggested that increased Fe content in mangrove soils could be attributed to the precipitation of the respective metal sulfide compounds in anaerobic sediments [25].

The selected mangrove plant species showed variation in AM spore density. An earlier study reported that spore density patterns may not reflect the activity of AM fungi in roots, but rather the tendency to sporulate along wide environmental conditions [26]. Other studies suggested that $\mathrm{P}$ availability [27], plant physiology, and turnover of plant roots [28] are among the drivers of AM fungal seasonality. Spore density showed variation, maximum in premonsoon and minimum in the monsoon season at both sites. Similar observations have been reported in earlier studies [29, 30]. Higher spore density in premonsoon season is thought to be an indication of root senescence and available nutrients, stimulating fungal sporulation as plant nutrient requirement is reduced [31]. Higher AM spore density in premonsoon may also be attributed to soil temperature, as previous studies $[32,33]$ suggested that high soil temperature favours AM fungal sporulation.
In the present study no significant correlation between relative abundance (RA) of dominant AM fungal species, and soil $\mathrm{pH}, \mathrm{P}$, or $\mathrm{EC}$ values suggests that AM fungi have a specific multidimensional niche determined by host plant species. This may affect variation between and within sites in AM fungal community composition [34]. Some reports suggest that AM fungi are obligately aerobic, flooding reduces sporulation [35], and total spore density correlates negatively with soil moisture [36]. Others have found higher values of total spore density in wet soils than in dry soils [37] and have suggested that high sporulation is a stress response to adverse or extreme environmental conditions.

Glomus species are known to be widely distributed and are commonly found in different geographical regions [38]. Furthermore, Glomus species are more adaptable to adjustment of sporulation patterns in varied environmental conditions [39] resulting in dominance. In our study, Acaulospora laevis was recorded in all of the three seasons at both study sites. The acidic nature of mangrove soils explains the presence of A. laevis in all the seasons as Acaulospora species are known to occur in acidic soils [40]. Based on RA, the dominant species, namely, A. laevis and $R$. intraradices, showed different patterns of sporulation and distribution. These differences in sporulation pattern may be attributed to plant phenological events including new root growth [41], flowering, and fruiting [42]. They may also suggest differences in AM functionality.

Multivariate analysis revealed that seasons and host coaffected AM fungal spore density and species richness, and 
TABle 5: Pearson correlation coefficient ( $r$ value) between spore density and species richness at the two study sites.

\begin{tabular}{lcccccc}
\hline Ecological parameters & Premonsoon & $\begin{array}{c}\text { Terekhol site } \\
\text { Monsoon }\end{array}$ & Postmonsoon & Premonsoon & $\begin{array}{c}\text { Zuari site } \\
\text { Monsoon }\end{array}$ & Postmonsoon \\
\hline SD versus SR & ${ }^{*} 0.726$ & 0.675 & 0.513 & ${ }^{*} 0.645$ & 0.326 & 0.342 \\
\hline
\end{tabular}

SD: spore density; SR: species richness; ${ }^{*}$ : significant at $P \leq 0.05$.

TABLE 6: Diversity measurements of AM fungal communities in different seasons at the two study sites.

\begin{tabular}{|c|c|c|c|}
\hline Study sites and ecological parameters & Premonsoon & Monsoon & Postmonsoon \\
\hline \multicolumn{4}{|l|}{ Terekhol site } \\
\hline Shannon-Weiner index $(H)$ & 0.795 & 0.358 & 0.852 \\
\hline Simpsons index of dominance $(D)$ & 0.93 & 0.79 & 0.97 \\
\hline Evenness $(E)$ & 0.40 & 0.32 & 0.52 \\
\hline \multicolumn{4}{|l|}{ Zuari site } \\
\hline Shannon-Weiner index $(H)$ & 0.927 & 0.361 & 0.774 \\
\hline Simpsons index of dominance $(D)$ & 0.99 & 0.784 & 0.99 \\
\hline Evenness $(E)$ & 0.48 & 0.32 & 0.51 \\
\hline
\end{tabular}

the seasons have a greater influence than host by analyses of $F$ values. The seasons and host are important factors influencing AM fungal spore density and species richness in natural ecosystems because the host plant can regulate carbon allocation to roots, produces secondary metabolites, and changes the soil environment during different seasons [9]. Beside seasons other factors such as disturbance [43], sporulation efficiency [44], and dormancy [45] are known to affect the abundance of AM fungal species. Seasonal diversity observed in the present study is higher than that in an earlier mangrove study in South China, where only six AM fungal species were reported [2]. Similarly, only four AM fungal species belonging to two genera in 16 aquatic and marshy plant species were reported from Goa, India [46]. In general the AM fungal diversity in wetland ecosystems is lower than in terrestrial ecosystems $[47,48]$. Preference of different host plants and dormancy may be factors attributing to lower diversity of AM fungi in wetlands [49].

\section{Conclusion}

Mangrove plant communities interact with rhizosphere soil and can modify edaphic properties. Similarly edaphic factors interact with plant communities and modify their composition. Consequently in this study there was no clearly observed separation between the plant and soil factors influence on AM fungal sporulation. Seasonal studies of AM fungi help to predict the conditions crucial for development of AM fungi. Further targeted ecological studies are needed to consider the combined effect of occurrence of AM fungi in the different phenological stages of mangroves to provide an accurate picture of AM fungal development and function prevailing in the given ecosystem. Our study suggests that the uneven spatial distribution of AM fungal spores and the complex structure of a mangrove ecosystem should be considered as major factors affecting the spore density of AM fungi in different seasons.

\section{Acknowledgment}

The authors gratefully acknowledge the financial assistance received from Planning Commission, Government of India, New Delhi, India, to carry out this study.

\section{References}

[1] B. Gopal and M. Chauhan, "Biodiversity and its conservation in the sundarban mangrove ecosystem," Aquatic Sciences, vol. 68, no. 3, pp. 338-354, 2006.

[2] Y. Wang, Q. Qiu, Z. Yang, Z. Hu, N. F. Y. Tam, and G. Xin, "Arbuscular mycorrhizal fungi in two mangroves in South China," Plant and Soil, vol. 33, no. 1, pp. 181-191, 2010.

[3] C. E. Lovelock, I. C. Feller, K. L. McKee, B. M. J. Engelbrecht, and M. C. Ball, "The effect of nutrient enrichment on growth, photosynthesis and hydraulic conductance of dwarf mangroves in Panama," Functional Ecology, vol. 18, no. 1, pp. 25-33, 2004.

[4] D. M. Alongi, "Present state and future of the world's mangrove forests," Environmental Conservation, vol. 29, no. 3, pp. 331-349, 2002.

[5] M. Cui and M. M. Caldwell, "Facilitation of plant phosphate acquisition by arbuscular mycorrhizas from enriched soil patches II. Hyphae exploiting root-free soil," New Phytologist, vol. 133, no. 3, pp. 461-467, 1996.

[6] G. Feng, F. S. Zhang, X. L. Li, C. Y. Tian, C. Tang, and Z. Rengel, "Improved tolerance of maize plants to salt stress by arbuscular mycorrhiza is related to higher accumulation of soluble sugars in roots," Mycorrhiza, vol. 12, no. 4, pp. 185-190, 2002.

[7] R. B. Zandavalli, L. R. Dillenburg, and V. D. Paulo, "Growth responses of Araucaria angustifolia (Araucariaceae) to inoculation with the mycorrhizal fungus Glomus clarum," Applied Soil Ecology, vol. 25, no. 3, pp. 245-255, 2004.

[8] M. G. A. van der Heijden, J. N. Klironomos, M. Ursic et al., "Mycorrhizal fungal diversity determines plant biodiversity, ecosystem variability and productivity," Nature, vol. 396, no. 6706, pp. 69-72, 1998.

[9] Y. Y. Su, X. Sun, and L. D. Guo, "Seasonality and host preference of arbuscular mycorrhizal fungi of five plant species in the inner 
mongolia steppe, China," Brazilian Journal of Microbiology, vol. 42, no. 1, pp. 57-65, 2011.

[10] T. Kumar and M. Ghose, "Status of arbuscular mycorrhizal fungi (AMF) in the Sundarbans of India in relation to tidal inundation and chemical properties of soil," Wetlands Ecology and Management, vol. 16, no. 6, pp. 471-483, 2008.

[11] R. S. Rao, Flora of Goa, Daman, Dadra and Nagar Haveli Volume I \& II.Botanical Survey of India, Deep Printers, New Delhi, India, 1985.

[12] A. Walkley and J. A. Black, "An examination of the Degtjareff method for determining soil organic matter and a proposed modification of the chromic titration method," Soil Science, vol. 37, pp. 29-38, 1934.

[13] R. H. Bray and L. T. Kurtz, "Determination of total, organic and available forms of phosphorus in soils," Soil Science, vol. 59, pp. 39-45, 1945.

[14] J. J. Hanway and H. Heidel, "Soil analysis method as used in Iowa State College soil testing laboratory," Iowa State College of Agriculture, vol. 57, pp. 1-31, 1952.

[15] W. L. Lindsay and W. A. Norvell, "Development of DTPA soil test for zinc, iron, manganese and copper," Soil Science Society of America Journal, vol. 42, pp. 421-428, 1978.

[16] J. W. Gerdemann and T. H. Nicolson, "Spore density of the Endogone species extracted from soil by wet sieving and decanting," Transactions of British Mycological Society, vol. 46, pp. 235-244, 1963.

[17] B. F. Rodrigues and T. Muthukumar, Arbuscular Mycorrhizae of Goa-A Manual of Identification Protocols, Goa University, Goa, India, 2009.

[18] N. C. Schenck and Y. Perez, Manual for the Identification of VA Mycorrhizal Fungi, University of Florida, Gainesville, Fla, USA, 1990.

[19] E. H. Simpson, "Measurement of diversity," Nature, vol. 163, no. 4148, p. 688, 1949.

[20] C. E. Shannon and W. Weaver, The Mathematical Theory of Communication, The University of Illinois Press, Urbana, Ill, USA, 1949.

[21] B. F. Rodrigues and N. Anuradha, "Arbuscular mycorrhizal fungi in Khazan land agro-ecosystem," in Frontiers in Fungal Ecology, Diversity and Metabolites, K. R. Sridhar, Ed., pp. 141-150, I.K. International, New Delhi, India, 2009.

[22] R. T. M. Padma and D. Kandaswamy, "Effect of interactions between VA mycorrhizae and graded levels of phosphorus on growth of papaya (Carica papaya)," in Current Trends in Mycorrhizal Research, B. L. Jalai and H. Chand, Eds., pp. 133-134, Haryana Agricultural University, Hisar, India, 1990.

[23] J. F. Liao, "The chemical properties of the mangrove Solonchak in the northeast part of Hainan Island," Acta Scientiarum Naturalium Universitatis, vol. 9, pp. 67-72, 1990.

[24] M. Stumm and J. J. Morgan, Aquatic Chemistry, John Wiley and Sons, New York, NY, USA, 3rd edition, 1996.

[25] R. W. Howarth, "Pyrite: its rapid formation in a salt marsh and its importance in ecosystem metabolism," Science, vol. 203, no. 4375, pp. 49-51, 1979.

[26] S. P. Miller and J. D. Bever, "Distribution of arbuscular mycorrhizal fungi in stands of the wetland grass Panicum hemitomon along a wide hydrologic gradient," Oecologia, vol. 119, no. 4, pp. 586-592, 1999.

[27] A. L. Ruotsalainen, H. Väre, and M. Vestberg, "Seasonality of root fungal colonization in low-alpine herbs," Mycorrhiza, vol. 12, no. 1, pp. 29-36, 2002.
[28] M. A. Lugo, M. E. G. Maza, and M. N. Cabello, "Arbuscular mycorrhizal fungi in a mountain grassland II: seasonal variation of colonization studied, along with its relation to grazing and metabolic host type," Mycologia, vol. 95, no. 3, pp. 407-415, 2003.

[29] S. S. Dhillion and R. C. Anderson, "Seasonal dynamics of dominant species of arbuscular mycorrhizae in burned and unburned sand prairies," Canadian Journal of Botany, vol. 71, no. 12, pp. 1625-1630, 1993.

[30] J. N. Gemma, R. E. Koske, and M. Carreiro, "Seasonal dynamics of selected species of V-A mycorrhizal fungi in a sand dune," Mycological Research, vol. 92, no. 3, pp. 317-321, 1989.

[31] S. P. Bentivenga and B. A. D. Hetrick, "Seasonal and temperature effects on mycorrhizal activity and dependence of cooland warm-season tallgrass prairie grasses," Canadian Journal of Botany, vol. 70, no. 8, pp. 1596-1602, 1992.

[32] D. S. Hayman, "Plant growth responses to vesicular-arbuscular mycorrhiza. VI. Effect of light and temperature," New Phytologist, vol. 73, pp. 71-78, 1970.

[33] A. Saravanakumar, M. Rajkumar, S. J. Serebiah, and G. A. Thivakaran, "Seasonal variations in physico-chemical characteristics of water, sediment and soil texture in arid zone mangroves of Kachchh-Gujarat," Journal of Environmental Biology, vol. 29, no. 5, pp. 725-732, 2008.

[34] E. M. Ahulu, A. Gollotte, V. Gianinazzi-Pearson, and M. Nonaka, "Cooccurring plants forming distinct arbuscular mycorrhizal morphologies harbor similar AM fungal species," Mycorrhiza, vol. 17, no. 1, pp. 37-49, 2006.

[35] T. Aziz and D. M. Sylvia, "Activity and species composition of arbuscular mycorrhizal fungi following soil removal," Ecological Applications, vol. 5, no. 3, pp. 776-784, 1995.

[36] R. C. Anderson, A. E. Liberta, and L. A. Dickman, "Interaction of vascular plants and vesicular-arbuscular mycorrhizal fungi across a soil moisture-nutrient gradient," Oecologia, vol. 64, no. 1, pp. 111-117, 1984.

[37] D. H. Rickerl, F. O. Sancho, and S. Ananth, "Vesiculararbuscular endomycorrhizal colonization of wetland plants," Journal of Environmental Quality, vol. 23, no. 5, pp. 913-916, 1994.

[38] J. C. Stutz, R. Copeman, C. A. Martin, and J. B. Morton, "Patterns of species composition and distribution of arbuscular mycorrhizal fungi in arid regions of southwestern North America and Namibia, Africa," Canadian Journal of Botany, vol. 78, no. 2, pp. 237-245, 2000.

[39] J. C. Stutz and J. B. Morton, "Successive pot cultures reveal high species richness of vesicular-arbuscular mycorrhizal fungi across a soil moisture nutrient gradient," Oecologia, vol. 64, pp. 111-117, 1996.

[40] L. K. Abbott and A. D. Robson, "Factors influencing the occurrence of vesicular-arbuscular mycorrhizas," Agriculture, Ecosystems and Environment, vol. 35, no. 2-3, pp. 121-150, 1991.

[41] W. E. van Duin, J. Rozema, and W. H. O. Ernst, "Seasonal and spatial variation in the occurrence of vesicular-arbuscular (VA) mycorrhiza in salt marsh plants," Agriculture, Ecosystems and Environment, vol. 29, no. 1-4, pp. 107-110, 1989.

[42] D. L. Stenlund and I. D. Charvat, "Vesicular arbuscular mycorrhizae in floating wetland mat communities dominated by Typha," Mycorrhiza, vol. 4, no. 3, pp. 131-137, 1994.

[43] P. Guadarrama and F. J. Alvarez-Sanchez, "Abundance of arbuscular mycorrhizal fungi spores in different environments in a tropical rain forest, Veracruz, Mexico," Mycorrhiza, vol. 8, no. 5, pp. 267-270, 1991. 
[44] Z. W. Zhao, "Population composition and seasonal variation of VA mycorrhizal fungi spores in the rhizosphere soil of four pteridophytes," Acta Botanica Yunnanica, vol. 21, pp. 437-441, 1999.

[45] C. Walker, C. W. Mize, and H. S. McNabb, "Populations of endogonaceous fungi at two locations in central Iowa," Canadian Journal of Botany, vol. 60, no. 12, pp. 2518-2529, 1982.

[46] K. P. Radhika and B. F. Rodrigues, "Arbuscular mycorrhizae in association with aquatic and marshy plant species in Goa, India," Aquatic Botany, vol. 86, no. 3, pp. 291-294, 2007.

[47] K. P. Radhika and B. F. Rodrigues, "Arbuscular mycorrhizal fungal diversity in some commonly occurring medicinal plants of Western Ghats, Goa region," Journal of Forestry Research, vol. 21, no. 1, pp. 45-52, 2010.

[48] D. Zhao and Z. Zhao, "Biodiversity of arbuscular mycorrhizal fungi in the hot-dry valley of the Jinsha River, Southwest China," Applied Soil Ecology, vol. 37, no. 1-2, pp. 118-128, 2007.

[49] X. He, S. Mouratov, and Y. Steinberger, "Spatial distribution and colonization of arbuscular mycorrhizal fungi under the canopies of desert halophytes," Arid Land Research and Management, vol. 16, no. 2, pp. 149-160, 2002. 

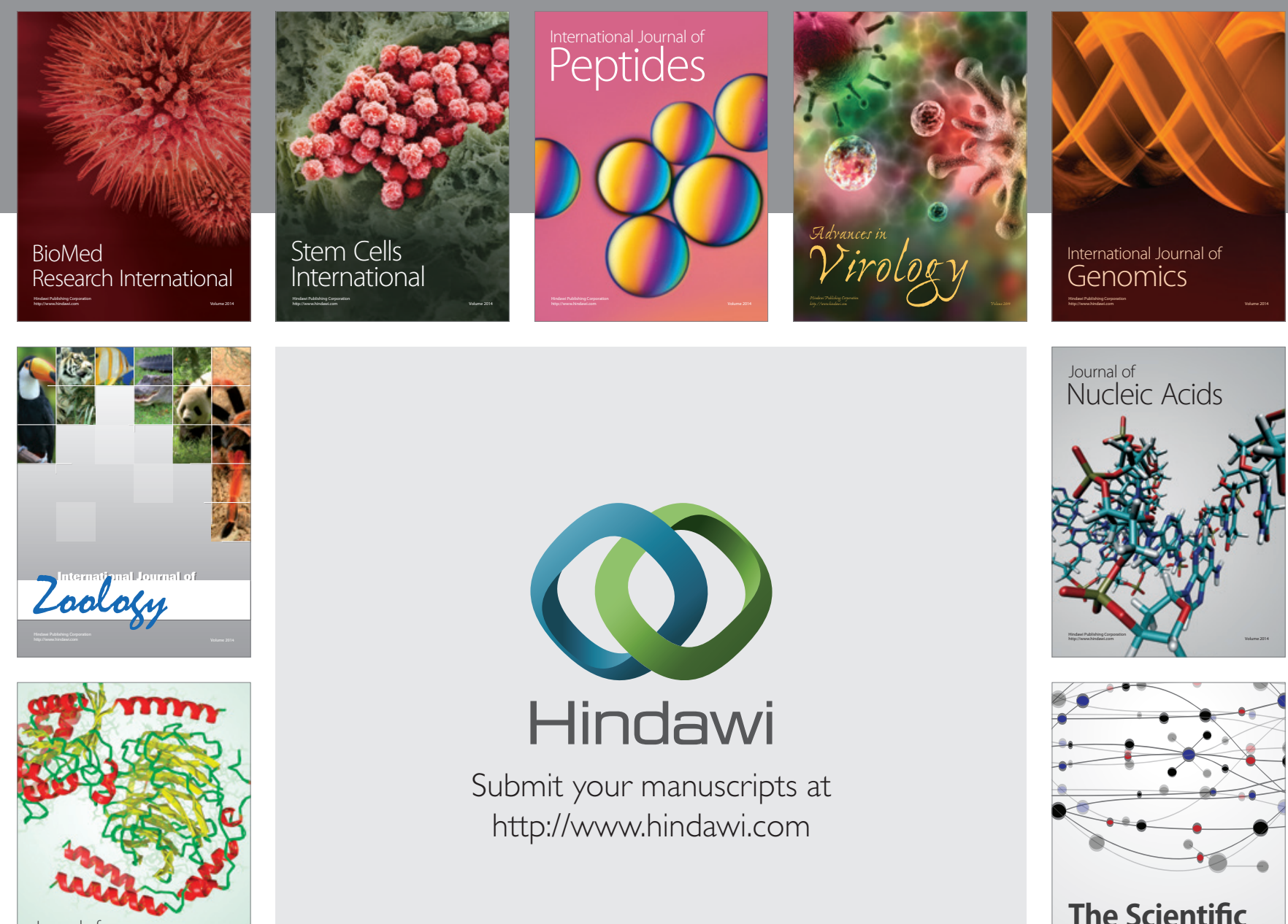

Submit your manuscripts at

http://www.hindawi.com

Journal of
Signal Transduction
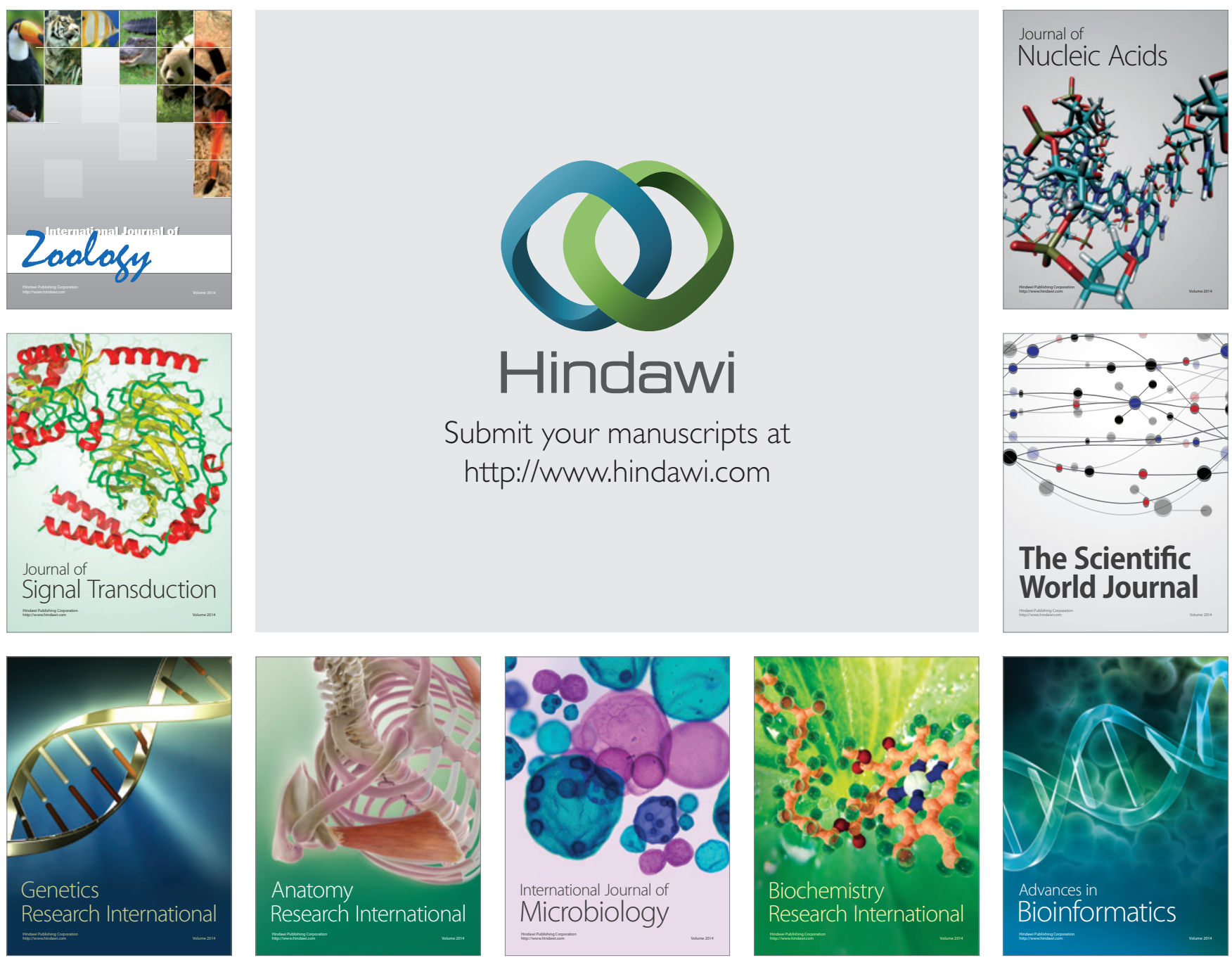

The Scientific World Journal
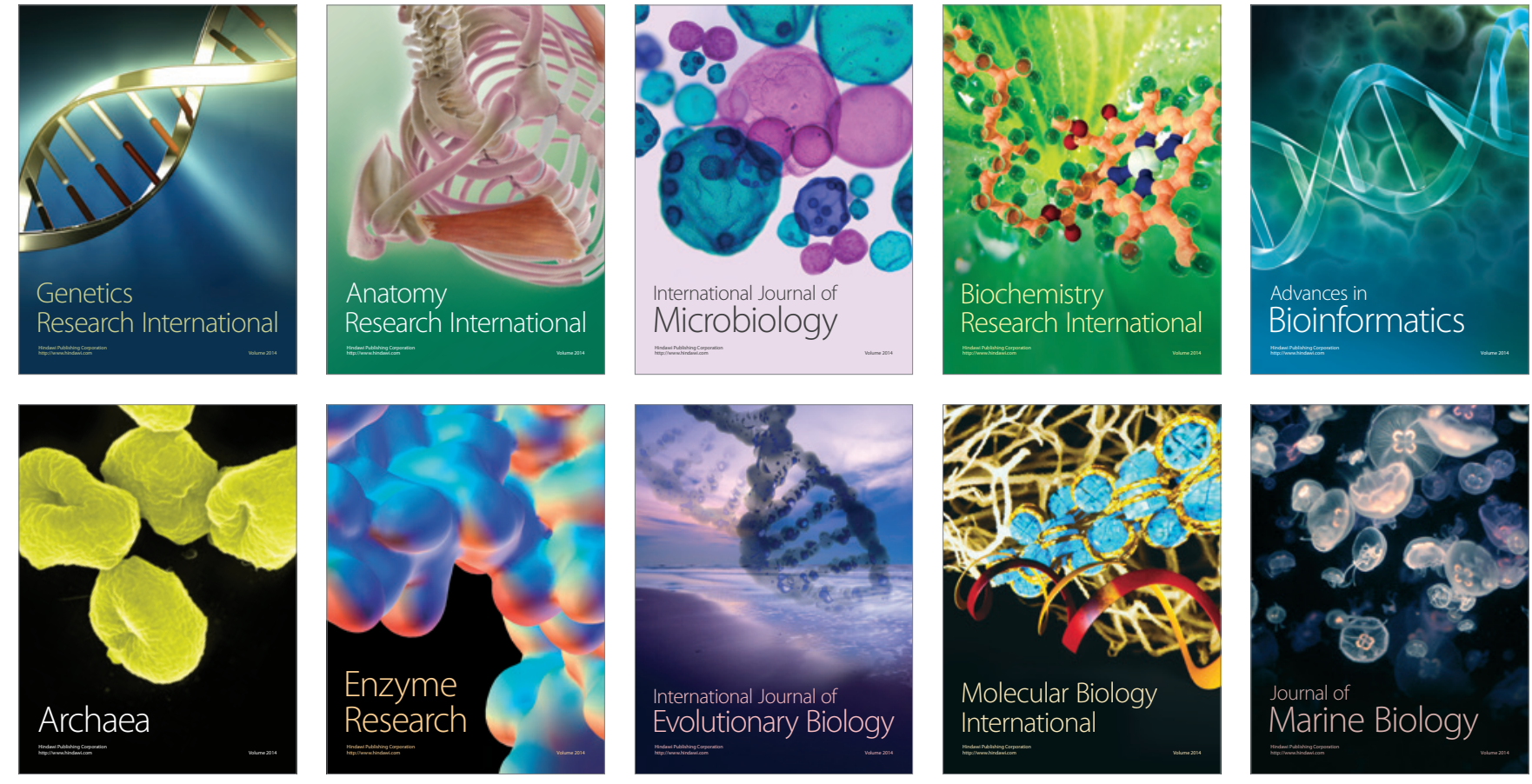